\title{
Impact of the East Asian summer monsoon on long-term variations in the acidity of summer precipitation in Central China
}

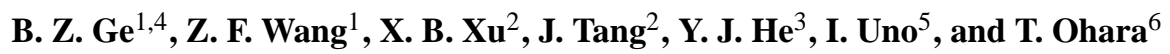 \\ ${ }^{1}$ State Key Laboratory of Atmospheric Boundary Layer Physics and Atmospheric Chemistry (LAPC), Institute of \\ Atmospheric Physics, Chinese Academy of Science, Beijing 100029, China \\ ${ }^{2}$ Key Laboratory for Atmospheric Chemistry, Centre for Atmosphere Watch and Services, Chinese Academy of \\ Meteorological Sciences, China Meteorological Administration, Beijing, China \\ ${ }^{3}$ Chinese Research Academy of Environmental Sciences, Beijing, China \\ ${ }^{4}$ Graduate University of the Chinese Academy of Sciences, Beijing, 100049, China \\ ${ }^{5}$ Research Institute for Applied Mechanics, Kyushu University, Fukuoka, Japan \\ ${ }^{6}$ National Institute of Environmental Science, Tsukuba, Japan
}

Received: 17 July 2010 - Published in Atmos. Chem. Phys. Discuss.: 19 August 2010

Revised: 8 December 2010 - Accepted: 8 February 2011 - Published: 21 February 2011

\begin{abstract}
The acidity of precipitation has been observed at stations of the Acid Rain Monitoring Network run by the China Meteorological Administration (CMA-ARMN) since 1992. Previous studies have shown that different long-term trends exist in different regions but detailed analysis of the causes of these is lacking. In this paper, we analyze summertime precipitation acidity data from the CMA-ARMN during 1992-2006 using EOFs and show that the summertime $\mathrm{pH}$ in China had different trends before and after 2000. The most significant decrease of $\mathrm{pH}$ is found in Central China. To investigate the causes of this decrease of $\mathrm{pH}$ in summer, we explore the relationship between changes in the $\mathrm{pH}$ value, the East Asian summer monsoon index, rainfall data, and pollutants emissions. We find that the East Asian summer monsoon can significantly affect the acidity of summer precipitation in Central China. In strong monsoon years, the $\mathrm{pH}$ in Central China is about 0.33 lower than that in weak monsoon years. Chemical transport model simulations using fixed emissions indicate that about $65 \%$ of the $\mathrm{pH}$ value difference (i.e., 0.22$)$ is related to the summer monsoon, and constitutes $18-36 \%$ of the observed $\mathrm{pH}$ change $(0.6 \sim 1.2)$ in Central China during 1992-2006. Further studies reveal a relationship between the $\mathrm{pH}$ in Central China and the rainfall in the middle and lower reaches of the Yangtze River (MLYR), which can explain about $24 \%$ of the variance of $\mathrm{pH}$ in Cen-
\end{abstract}

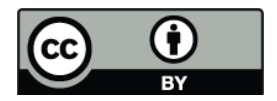

Correspondence to: Z. F. Wang (zifawang@mail.iap.ac.cn) tral China. Simulations using an annually varying emission inventory show that at least $60 \%$ of the variation in precipitation acidity in Central China can be attributed to changes in pollutant emissions. Therefore, the increase in emissions of acidic species is the most important cause for the observed decrease of $\mathrm{pH}$ in Central China, and changes in meteorological factors, such as rainfall and other parameters related to the East Asian summer monsoon, play a less important but still significant role.

\section{Introduction}

Acid rain has been one of the most significant environmental problems in China since the late 1970s. Rapid economic development and population growth has lead to increases in the emission and subsequent deposition of sulfur, and widespread acid rain was observed in southern and southwestern China between the 1980s and the mid 1990s (Ding et al., 1997, 2004; Wang and Wang, 1995, 1996; Zhao et al., 1988; Huang et al., 1995). The rapid expansion of the acid rain zone exposes citizens and ecosystems to great risk in southern and southwestern China, and after the mid 1990s the region of acid rain extended into Central China (Zhang et al., 2007; Xie et al., 2009). In order to reduce the emission of $\mathrm{SO}_{2}$ and mitigate acid rain in China, the Chinese government issued the "Atmospheric Pollution Prevention and Control Act of the Peoples Republic of China" in 1995. Following

Published by Copernicus Publications on behalf of the European Geosciences Union. 
this act, a national control measure known as "Two Control Zones" (TCZ) was enacted in 1998 with the aim of strengthening control of $\mathrm{SO}_{2}$ emissions (Liu et al., 1998). Meanwhile, municipal governments attempted to improve air quality in different ways to strengthen the control of the emissions of gaseous pollutants and particulate matter. Although these efforts had some positive effects in the first few years, rapid economic development and an increased demand for energy have caused further increases in the emissions of $\mathrm{SO}_{2}$ and $\mathrm{NO}_{2}$ over the last decade. A large number of reports (Zhang et al., 2008; Xie et al., 2009; Wang and Xu, 2009; SEPA; Gao et al., 2009; Larssen et al., 2006) reveal that nationwide emissions of $\mathrm{SO}_{2}$ and $\mathrm{NO}_{2}$ have increased significantly since 2000 , following the temporary decrease in emissions in the 1990s.

Most studies on acid rain link its variation to the emissions and transport of $\mathrm{SO}_{2}$ and $\mathrm{NO}_{2}$ (Khemani et al., 1994; Browning et al., 1991; Wang et al., 2007; Vogt et al., 2006; Quan et al., 2007; Liu et al., 2008; Larssen et al., 2006), but few consider the impacts of climatic conditions (Xie et al., 2009; Dayana and Lamb, 2008; Rai et al., 2009; Yeung et al., 2007; Tiwari et al., 2007; Ravichandran and Padmanabhamurty, 1994; Davies et al., 1991). Previous studies have shown that before the 1990s acid rain occurred mainly in southern and southwestern regions of China. More recently, however, acid rain has seriously affected the central parts of China, especially in eastern areas (Xie et al., 2009). Tang et al. (2010) used the Man-Kendall method to obtain a trend in precipitation acidity in China, and show that during 20002006 acid rain moved from southwestern to eastern and central China. We analyzed the change in precipitation acidity in China between 1992 and 2006, and found that the most distinct increase occurred in Central China. What are the causes of this increase and are they related to changes in climatic conditions? In this paper, we report the potential contributions of the summer monsoon and rainfall in the middle and lower Yangtze River regions to precipitation acidity in Central China. We also evaluate the influence of variations in emissions on changes in the acidity of precipitation in Central China.

\section{Data and methodologies}

\subsection{Data}

It is well known that soil aerosol/dust originating from northern China can affect precipitation acidity over almost all of the country in winter and springtime under conditions of continental outflow during the East Asian winter monsoon (Wang et al., 2002; Rodhe et al., 2002; Wai and Tanner, 2005; Yeung et al., 2007). In order to exclude this factor we choose to focus on summertime (from June to August) and study the contributions from the East Asian summer monsoon and pol- lution to the variation in the acidity of precipitation in Central China.

Precipitation acidity, conductivity and rainfall are observed using polyethylene polymer bucket of $40 \mathrm{~cm}$ diameter at stations of the Acid Rain Monitoring Network run by the China Meteorological Administration (CMA-ARMN), which share the facilities of the meteorological observation stations, and are normally located in suburb of a city or a town, thus much less directly influenced by urban emissions. During the period 1992-2006, event samples were collected before 2005 and daily precipitation samples were collected during 2006 at 88 network stations. Strict quality assurance and quality control was applied to the dataset from the CMAARMN. Data for 14 of the 88 stations were found to be unsuitable for long-term trend analysis (Tang et al., 2007, 2010) and precipitation acidity data from the 74 remaining stations are used in this study. In details, 37 among the 74 sites are located in relatively sparsely populated areas, including $3 \mathrm{GAW}$ (Global Atmosphere Watch) regional stations and 3 weather stations on top of mountains, the rest 37 are city or near-city sites. Although the sites are of different characteristics, they are mixed and distributed in different regions. In this paper, we focus on variations of precipitation acidity and meteorological parameters in larger regions and the relationship between these quantities. The quality of data from all the 74 sites was checked by series procedures (Tang et al., 2010) and is believed meeting our purpose. For meteorological data we use reanalysis data for $850 \mathrm{hPa}$ wind fields from the National Centers for Environmental Prediction (NCEP) and rainfall at 753 stations selected by CMA. To define the monsoon intensity and to investigate the influence of the monsoon on precipitation acidity in China, we used a dynamical normalized seasonality Monsoon Index (MI), which was developed by $\mathrm{Li}$ and Zeng (2002) on the basis of grid-by-grid and season-by-season calculations of the climatological wind field.

\subsection{Modeling}

The modeling system used in this study is CMAQ version 4.4 (Byun and Ching, 1999) driven by meteorological fields calculated by the Regional Atmospheric Modeling System (RAMS) Version 4.3 (Cotton et al., 2003; Pielke et al., 1992), with initial and boundary conditions defined by NCEP reanalysis data. The horizontal resolution of the model is $80 \mathrm{~km}$, and there are 19 layers in the vertical following a sigma-z coordination system up to $23 \mathrm{~km}$, the modeling domain is shown as sector area in Fig. 2 (for more details see Yamaji et al., 2006). The model uses the Regional Emission Inventory in Asia (Ohara et al., 2007), which is based on energy statistics, emission factors, and other socioeconomic information and covers the years 1980-2003 (He et al., 2007, 2008; Yamaji et al., 2006). For the purpose of comparison, we conducted three simulations to derive $\mathrm{SO}_{2}$, $\mathrm{NO}_{2}, \mathrm{SO}_{4}^{2-}$ and $\mathrm{NO}_{3}^{-}$concentrations as monthly averages 

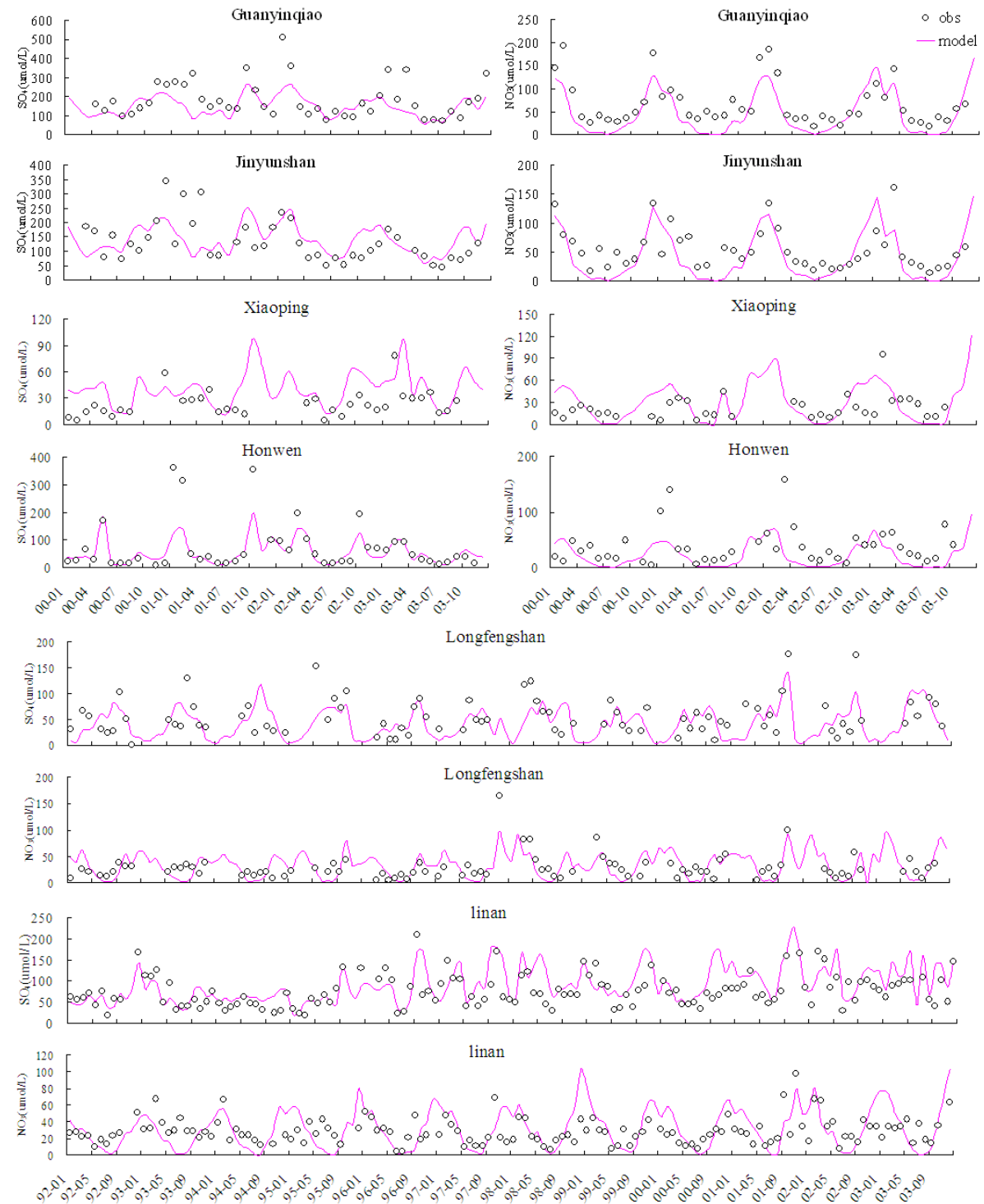

Fig. 1. Time series of modeled and observed monthly volume-weighted mean concentrations of sulfate and nitrate for EANET sites and GAW background stations.

for 1980-2003, but do not continue beyond 2003 in the absence of a suitable emission inventory. In the first simulation annually varying meteorological conditions were used along with the 2000 emission inventory, that is, only meteorological conditions change (hereafter MC); in the second, meteorological conditions for 2000 were used along with annuallyvarying emissions (hereafter EC); and in the third both meteorological conditions and emissions varied from year to year (hereafter Normal). It is worthy to mention that, we aimed to exclude the influence of pollutants emission for MC, and the meteorological factors for EC. According to that, the lowest emission and the modest value of summer monsoon in 2000 is ideal for our purpose.

The CMAQ model is widely used and is well validated with measurements from Chinese sites, e.g., Tieshanping in the Sichuan basin and Caijiatang in Hunan province (Quan et al., 2008), and it was found that simulated $\mathrm{SO}_{2}$ and $\mathrm{SO}_{4}^{2-}$ agree well with observations. Ohara (2010) found that the model can reproduce the observed temporal variations in monthly wet deposition of $\mathrm{SO}_{4}^{2-}$ at long-term acid deposition monitoring sites in East Asia since 1988. Lin et al. (2008) using this model to investigate the Long-range transport of acidifying substances in East Asia and found the model is able to capture major spatial and seasonal variations of $\mathrm{SO}_{2}$, $\mathrm{NO}_{2}$ and wet sulfate and nitrate deposition over East Asia, although there exist an underestimation on nitrate caused by the uncertainties in emission of precursors for nitrates. In addition, many studies have validated $\mathrm{O}_{3}$ and related species, which affect atmospheric oxidation, using measurements at EANET observation stations (Tanimoto et al., 2009; 


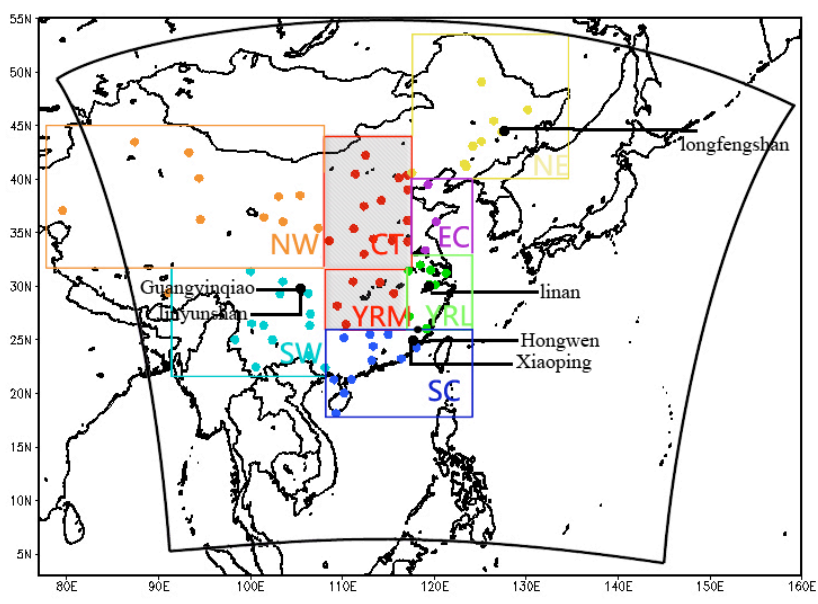

Fig. 2. Distribution of stations of CMA-ARMN and four EANET and two GAW stations marked by black dot, the shadow area in CT and YRM means the key area of our study, modeling domain is sector area.

Ohara et al., 2008), at the mountain sites Taishan, Huashan and Huangshan in China (He et al., 2008) and observations during the TRACE-P measurement campaign (Zhang et al., 2006b). These studies all show that the model can reproduce the tempo-spatial distributions of these species reasonably well. Thus, the model reproduces many of the important features of $\mathrm{SO}_{2}$ and $\mathrm{SO}_{4}^{2-}$ chemistry seen in the observations (Zhang et al., 2004; Zhang et al., 2006a). We have also compared the rainwater concentrations of $\mathrm{SO}_{4}^{2-}$ and $\mathrm{NO}_{3}^{-}$from the CMAQ model with four EANET observation stations in China, e.g., Hongwen and Xiaoping in Xiamen and Guanyinqiao and Jinyunshan in Chongqin, and two GAW sites, e.g., Linan in Yangtze River Delta and Longfengshan in northeast of China, and the trends of our model results are similar to that observed (see Fig. 1). The correlations between model and observations were greater than 0.5 (significant at the $95 \%$ level) and the bias of the mean values were less than $30 \%$ (see Table 1).

\subsection{Volume weighted average method}

The volume weighted average (VWA) value (Huang et al., 2008; Yeung et al., 2007; Seqheira and Lai, 1998) of $\mathrm{pH}$ is used, as this eliminates the influence of different rainfall intensities on the $\mathrm{pH}$. VWA $\mathrm{pH}$ at a station in a certain period is calculated by multiplying the volume of precipitation collected using the equation

$\mathrm{pH}_{\mathrm{VWA}}=-\log \left(\sum\left(10^{-\mathrm{pH}_{\mathrm{i}}} \times \mathrm{V}_{i}\right) / \sum \mathrm{V}_{i}\right)$

where $\mathrm{pH}_{\mathrm{VWA}}$ represents the volume weighted average $\mathrm{pH}$, and $\mathrm{pH}_{i}$ and $\mathrm{V}_{i}$ are the $\mathrm{pH}$ value and sample volume of the sample $i$, respectively.

\subsection{EOFs and the SVD method}

Empirical Orthogonal Functions (EOFs) are a set of independent and orthonormal eigenvectors that most efficiently represent a given set of data. The objective of the method is to split the temporal variance of spatially distributed data into orthogonal spatial patterns called EOFs or empirical orthogonal models. The relative importance of any individual eigenvector to the total variance in the field is measured by its associated eigenvalue or variance contribution. Each eigenvector, which may represent the spatial patterns of its variance, is associated with a series of time coefficients that describe the time evolution of that particular eigenvector (Gianelli et al., 2007; Calbet and Schlussel, 2006). In Sect. 3.1.1, the changes of summer precipitation $\mathrm{pH}$ in time and space are performed by this method.

Singular Value Decomposition (SVD) aims to find the linear combination or coupling mode of two sets of data. The objective is to separate the highly correlated areas of these two set of data (Jordi et al., 2009; Alter et al., 2000). The SVD was firstly used in diagnosing the relationship between monthly surface temperature in America and sea level pressure in north Pacific (Prokasha, 1976). After that, a lot of studies (Wang and Chen, 2004; Ding and Jiang, 1996) have used SVD analysis to investigate the correlations among meteorological parameters, i.e., rainfall, $u$ and $v$ wind, SST, and even aerosol (Shi et al., 2007). It is one of the best tools to study the correlations of two factors with large number of spatial and temporal data. Using this method, we can obtain a series of left and right singular vectors, standing for two factors respectively. The SVD defines the relations of left (right) variable or left (right) factor and time coefficients of right (left) singular vector (of the other factor) as the left (right) heterology correlation coefficients field. This one pair of heterology correlation coefficients field represent one kind of distribution of correlations between two factors, the area where correlated significantly is the key area of interaction between two factors. Thereafter, a pair of heterology correlation coefficients field stands for one type of relationship of two factors to some extent. We used the SVD method to investigate the relationship between rainfall in the middle and lower reaches of the Yangtze River (MLYR) and pHVwA in Central China.

\section{Result and discussion}

\subsection{Description of the dataset}

\subsubsection{Spatial patterns of VWA pH}

We divide mainland China into eight regions, shown in Fig. 2: the middle reaches of the Yangtze River (YRM, 109$117^{\circ} \mathrm{E}, 26-32^{\circ} \mathrm{N}$ ); lower reaches of Yangtze River (YRL, $117-123^{\circ} \mathrm{E}, 26-33^{\circ} \mathrm{N}$ ); Southern China (SC, $109-123^{\circ} \mathrm{E}$,

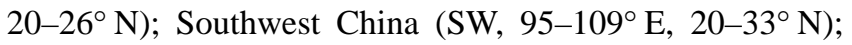


Table 1. Statistics of model results and observations. ( $N$, std, and $R$ represent the number of months, standard deviation, and correlation coefficient, respectively).

\begin{tabular}{|c|c|c|c|c|c|c|}
\hline \multicolumn{2}{|c|}{ Guanyinqiao } & $N$ & Mean $\left(\mu \mathrm{mol} \mathrm{L}{ }^{-1}\right)$ & std & Error & $R$ \\
\hline \multirow{2}{*}{$\mathrm{SO}_{4}^{2-}$} & Model & 48 & 161.5 & 52.55 & \multirow{2}{*}{$-16.07 \%$} & \multirow{2}{*}{0.60 (sig. $95 \%)$} \\
\hline & Obs & 37 & 192.4 & 69.03 & & \\
\hline \multirow{2}{*}{$\mathrm{NO}_{3}^{-}$} & Model & 48 & 48.6 & 46.71 & \multirow{2}{*}{$29.26 \%$} & \multirow{2}{*}{0.84 (sig. $95 \%)$} \\
\hline & Obs & 48 & 68.7 & 49.82 & & \\
\hline \multicolumn{7}{|c|}{ Jinyunshan } \\
\hline \multirow{2}{*}{$\mathrm{SO}_{4}^{2-}$} & Model & 48 & 141.5 & 47.92 & \multirow{2}{*}{$3.98 \%$} & \multirow{2}{*}{0.43 (sig. $95 \%$ ) } \\
\hline & Obs & 44 & 136.1 & 73.54 & & \\
\hline \multirow{2}{*}{$\mathrm{NO}_{3}^{-}$} & Model & 48 & 43.3 & 44.39 & \multirow{2}{*}{$-23.17 \%$} & \multirow{2}{*}{0.78 (sig. $95 \%)$} \\
\hline & Obs & 47 & 56.4 & 37.95 & & \\
\hline \multicolumn{7}{|c|}{ Hongwen } \\
\hline \multirow{2}{*}{$\mathrm{SO}_{4}^{2-}$} & Model & 48 & 78.5 & 34.99 & \multirow{2}{*}{$10.91 \%$} & \multirow{2}{*}{0.65 (sig. $95 \%)$} \\
\hline & Obs & 43 & 69.9 & 63.16 & & \\
\hline \multirow{2}{*}{$\mathrm{NO}_{3}^{-}$} & Model & 48 & 33.0 & 29.81 & \multirow{2}{*}{$-11.80 \%$} & \multirow{2}{*}{0.50 (sig. $95 \%)$} \\
\hline & Obs & 44 & 37.4 & 32.81 & & \\
\hline \multicolumn{7}{|c|}{ Xiaoping } \\
\hline \multirow{2}{*}{$\mathrm{SO}_{4}^{2-}$} & Model & 48 & 38.2 & 17.63 & \multirow{2}{*}{$69.13 \%$} & \multirow{2}{*}{0.47 (sig. $95 \%)$} \\
\hline & Obs & 35 & 22.6 & 14.66 & & \\
\hline \multirow{2}{*}{$\mathrm{NO}_{3}^{-}$} & Model & 48 & 22.7 & 23.12 & \multirow{2}{*}{$2.76 \%$} & \multirow{2}{*}{$0.60(\operatorname{sig} .95 \%)$} \\
\hline & Obs & 36 & 22.1 & 16.39 & & \\
\hline \multicolumn{7}{|c|}{ Linan } \\
\hline \multirow{2}{*}{$\mathrm{SO}_{4}^{2-}$} & Model & 144 & 91.2 & 42.34 & \multirow{2}{*}{$20.28 \%$} & $062(\sin 09 \%)$ \\
\hline & Obs & 134 & 75.8 & 38.01 & & $0.02(\operatorname{sig.99\% )}$ \\
\hline & Model & 144 & 31.5 & 23.88 & $1102 \%$ & $050($ sio $99 \%)$ \\
\hline $\mathrm{NO}_{3}$ & Obs & 135 & 28.1 & 15.44 & $11.92 \%$ & $0.50($ sig. $99 \%)$ \\
\hline Long & nshan & & & & & \\
\hline $\mathrm{SO}^{2-}$ & Model & 144 & 41.2 & 42.34 & & 047 (cis $00 \%)$ \\
\hline $\mathrm{SO}_{4}$ & Obs & 86 & 54.8 & 29.34 & $24.91 \%$ & $0.4 /(\operatorname{sig} .99 \%)$ \\
\hline & Model & 144 & 33.2 & 23.79 & $2225 \%$ & $053(\operatorname{sio} 99 \%)$ \\
\hline $\mathrm{NU}_{3}$ & Obs & 91 & 27.2 & 22.85 & $22.25 \%$ & $0.53(\operatorname{sig.99\% )}$ \\
\hline
\end{tabular}

Center of China $\left(\mathrm{CT}, 109-117^{\circ} \mathrm{E}, 32-42^{\circ} \mathrm{N}\right)$; East China $\left(\mathrm{EC}, 117-123^{\circ} \mathrm{E}, 33-40^{\circ} \mathrm{N}\right)$; Northeast China (NE, 117$135^{\circ} \mathrm{E}, 40-55^{\circ} \mathrm{N}$ ); and Northwest China (NW, 72-109 $\mathrm{E}$, $\left.33-49^{\circ} \mathrm{N}\right)$. Statistics are collected for the whole country and for these different regions. Most of stations are distributed nearly equidistantly in Central and East China, where acid rain occurs at high frequencies. Although stations in Northwest China are sporadic and unevenly distributed, our results may not be significantly distorted since acid rain occurs only very scarcely in that region. The results for $\mathrm{pH}_{\mathrm{VWA}}$, together with the arithmetic mean $\mathrm{pH}$, rainfall, and the number of stations, are listed in Table 2. As can be seen in the table, the lowest $\mathrm{pH}$ value is in SW and YRM, while the highest is in $\mathrm{NW}$ and NE for both $\mathrm{pH}$ averaging methods. In this study, we focus on YRM and CT, and call them Central China.
In the following analysis, we use $\mathrm{pH}_{\mathrm{VwA}}$ as it eliminates the influence of different rainfall intensities. Fig. 3a shows the spatial patterns of $\mathrm{pH}_{\mathrm{VWA}}$ in China during the summers of 1992-2006 (using Cress-Man interpolation method for mapping the spatial patterns of $\mathrm{pH}_{\mathrm{VWA}}$, and the same below). It is clear that acid rain occurred mainly in the south of China in summer during this period, with the most severe acid rain in Sichuan and Guizhou provinces, in the southwestern part of China. The other severe acid rain areas are the Yangtze River Delta, northwestern Guangxi and the Pearl River Delta, which are located in southeastern and southern China. This distribution is similar to that found by Xie et al. (2009).

The changes in $\mathrm{pH}_{\mathrm{VWA}}$ during 1992-2006 are shown in Fig. 3b. In southwestern China, the acidity of precipitation decreases significantly during 1992-2006, with $\mathrm{pH}$ 
Table 2. $\mathrm{pH}_{\mathrm{VWA}}$ and mean $\mathrm{pH}$ in summer during 1992-2006.

\begin{tabular}{lcccccccc}
\hline Defined region & YRM & YRL & SW & SC & NW & NE & CT & EC \\
\hline pHVWA $^{*}$ & 4.75 & 4.85 & 4.73 & 4.81 & 5.43 & 5.49 & 5.13 & 5.05 \\
mean-pH** & 4.79 & 4.89 & 4.75 & 4.86 & 5.74 & 5.55 & 5.34 & 5.41 \\
Rainfall(mm)*** & 422.4 & 522.5 & 487.1 & 545.7 & 122.1 & 370.4 & 340.8 & 423.1 \\
Number of stations & 6 & 8 & 14 & 11 & 10 & 9 & 13 & 3 \\
\hline
\end{tabular}

*VWA average $\mathrm{pH}$

*direct average $\mathrm{pH}$

**total rainfall in summer per year per station

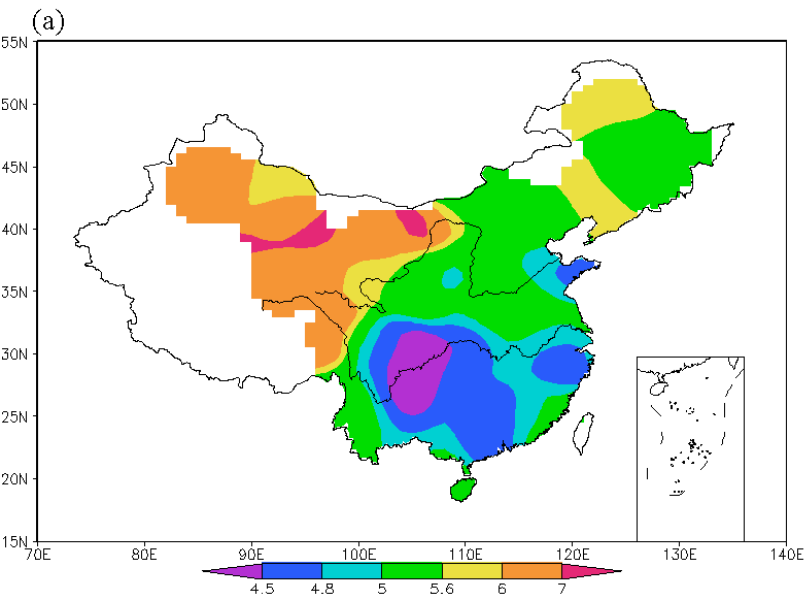

(b)

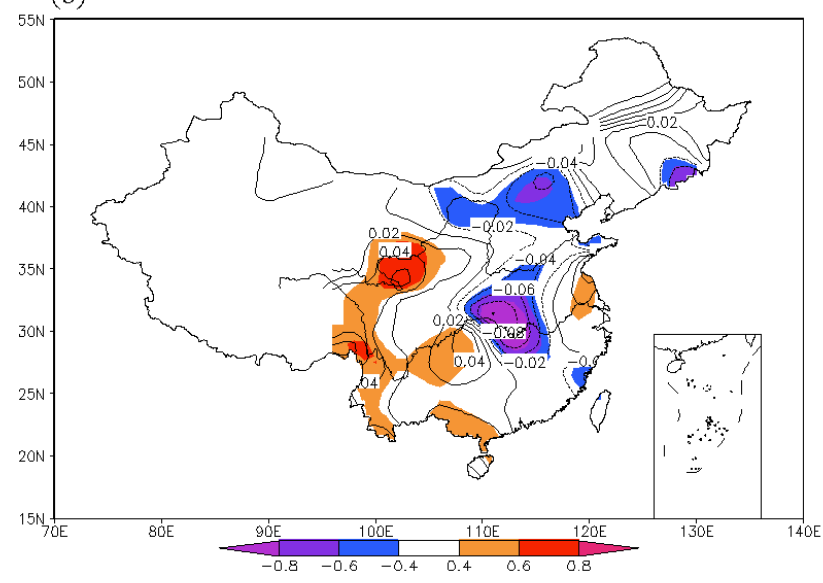

Fig. 3. Spatial patterns of the $\mathrm{pH}_{\mathrm{VWA}}$ (a) and the changes in pHVwA in China during the summer time of 1992-2006 (b). The shadowed color areas in (b) indicate the areas with changes significant at $90 \%$ level $(\alpha=0.10)$ and the contour lines and colors represent the changes of $\mathrm{pH}$ per year and correlation coefficient.

increasing by $0.3-0.6$ (at $\alpha=0.10$ ), However, a substantial increase in the acidity of precipitation in summer was observed in Central China, as shown in Fig. $3 \mathrm{~b}$ and in (Tang et al., 2010), with the $\mathrm{pH}$ value decreasing by $0.6-1.2$ (at $\alpha=$ $0.10)$.
Using the EOF method, the summer $\mathrm{pH}$ dataset from the CMA-ARMN stations is separated into a set of spatial functions (or EOF eigenvectors) and a series of time weighting coefficients. Figure $4 a$ and $b$ shows the spatial distribution of the EOF eigenvectors and the variation of the time weighting coefficients, respectively. The variance contributions from the first EOFs eigenvectors of the original $\mathrm{pH}$ dataset is greater than $99 \%$, and its spatial patterns are similar to those of pHVwA (Shi et al., 2007; Gu et al., 2007) (see Fig. 3a). The variation in the time weighting coefficients in Fig. 4b symbolizes the overall variation in the acidity of summer precipitation in China. The variation in the time weighting coefficients follows a parabola, and can be divided into two different periods, i.e., 1992-1999 and 2000-2006., with pH increasing between 1992 and 1999 and decreasing between 2000 and 2006. This general trend based on summertime data is consistent with that obtained from the whole dataset by Tang et al. (2010).

To further investigate regional differences in the trends of acid rain in China, we calculated $\mathrm{pH}$ VwA for the periods 1992-1999 and 2000-2006. The spatial distributions of the calculated $\mathrm{pH}$ vwA values for the two periods are shown in Fig. 5a and b, and the differences between the distributions for both periods are shown in Fig. 5c. In southeastern China, the area with $\mathrm{pH}_{\mathrm{VWA}}$ lower than 4.8 is significantly larger during 2000-2006 than during 1992-1999, indicating a worsening trend of acid rain in this area. As shown in Fig. 5c, the trend of precipitation acidity is very different from region to region. The contrasting trends become clearer on drawing a southeast-northwest dividing line from $22^{\circ} \mathrm{N}$, $112^{\circ} \mathrm{E}$ to $42^{\circ} \mathrm{N}, 105^{\circ} \mathrm{E}$. Northeast of the line, the acidity of precipitation increased (pH decreased) from 1992-1999 to 2000-2006, while southwest of the line, the opposite trend occurred. The most distinct acidification trends are found in Central China. In the SW area, the precipitation acidity decreased significantly (significant at a 90\% level) from 19921999 to $2000-2006$.

\subsubsection{Acidity of precipitation in different areas}

Figure 6 shows the time series of monthly $\mathrm{pH}_{\mathrm{VWA}}$ in summer during 1992-2006 for different regions. In SW, the $\mathrm{pH}_{\mathrm{VWA}}$ 

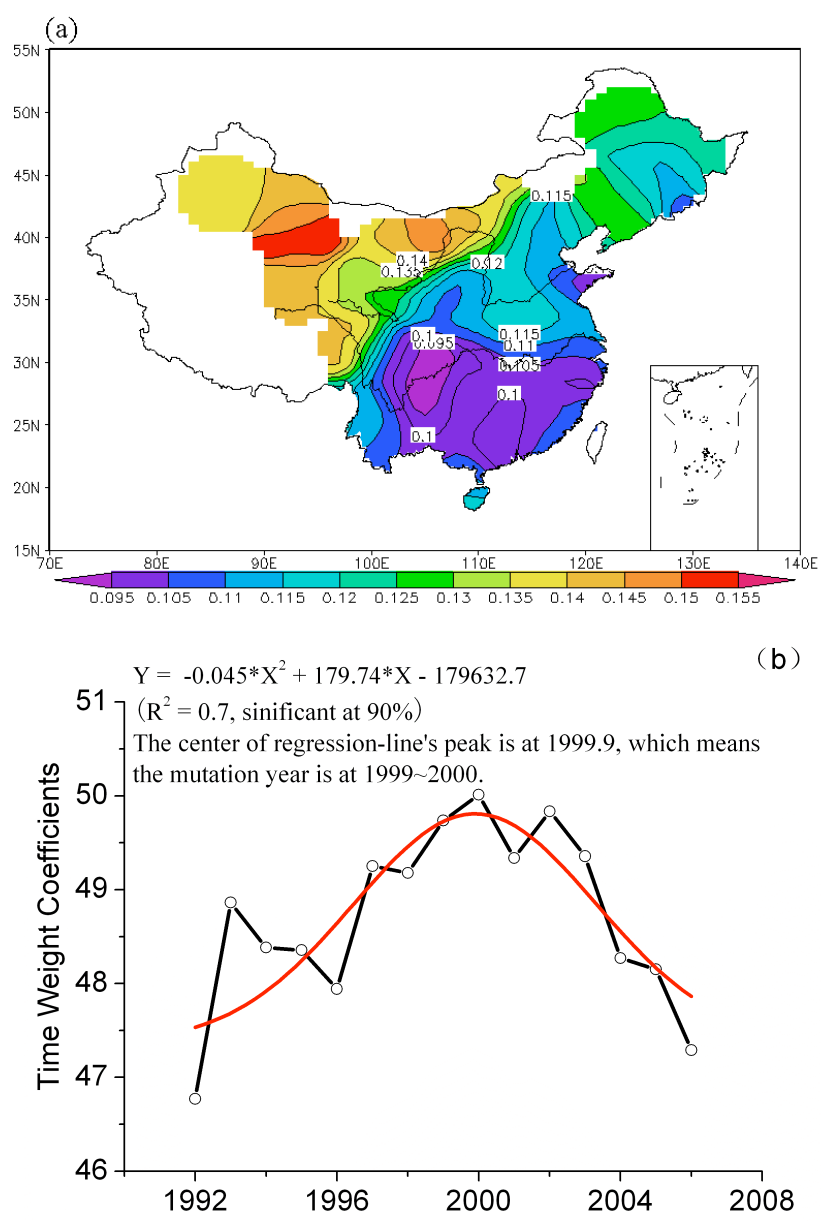

Fig. 4. Spatial distributions of the EOF eigenvectors of $\mathrm{pH}$ original dataset (a) and variation of time weighting coefficient (b). The black line with circles represents the actual variation of the time weight coefficients and the red line shows the regression line with $R^{2}=$ 0.70 (significant at $90 \%$ level).

of precipitation increased gradually during 1992-2006, consistent with Tang et al. (2010) and Xie et al. (2009); in SC, NW and CT, pHVwA first showed an increase and then a decrease, similar to the general trend over the whole country; in $\mathrm{NE}, \mathrm{pH}$ VwA decreased consistently. In CT, $\mathrm{pH}$ VwA showed a regular pattern, with the lowest $\mathrm{pH}_{\mathrm{VWA}}$ almost always occurring in August. In summer, the mean rain $\mathrm{pH}$ values decreased from June to August over CT. The substantial increase in the acidity of precipitation in this area might be explained by the following mechanism: developed cities inland emit heavy air pollution, in particular $\mathrm{SO}_{2}$ and $\mathrm{NO}_{\mathrm{x}}$, and this pollution is transported to Central China under summertime winds, leading to accumulation and to an increase in the acidity of precipitation, especially in years with a strong summer monsoon. Mean while, the strong summer monsoon can also decrease the volume of rainfall in MLYR which may further decrease the wet deposition of acidic pollutants in local and increase the transporting to Central China and then acidity of
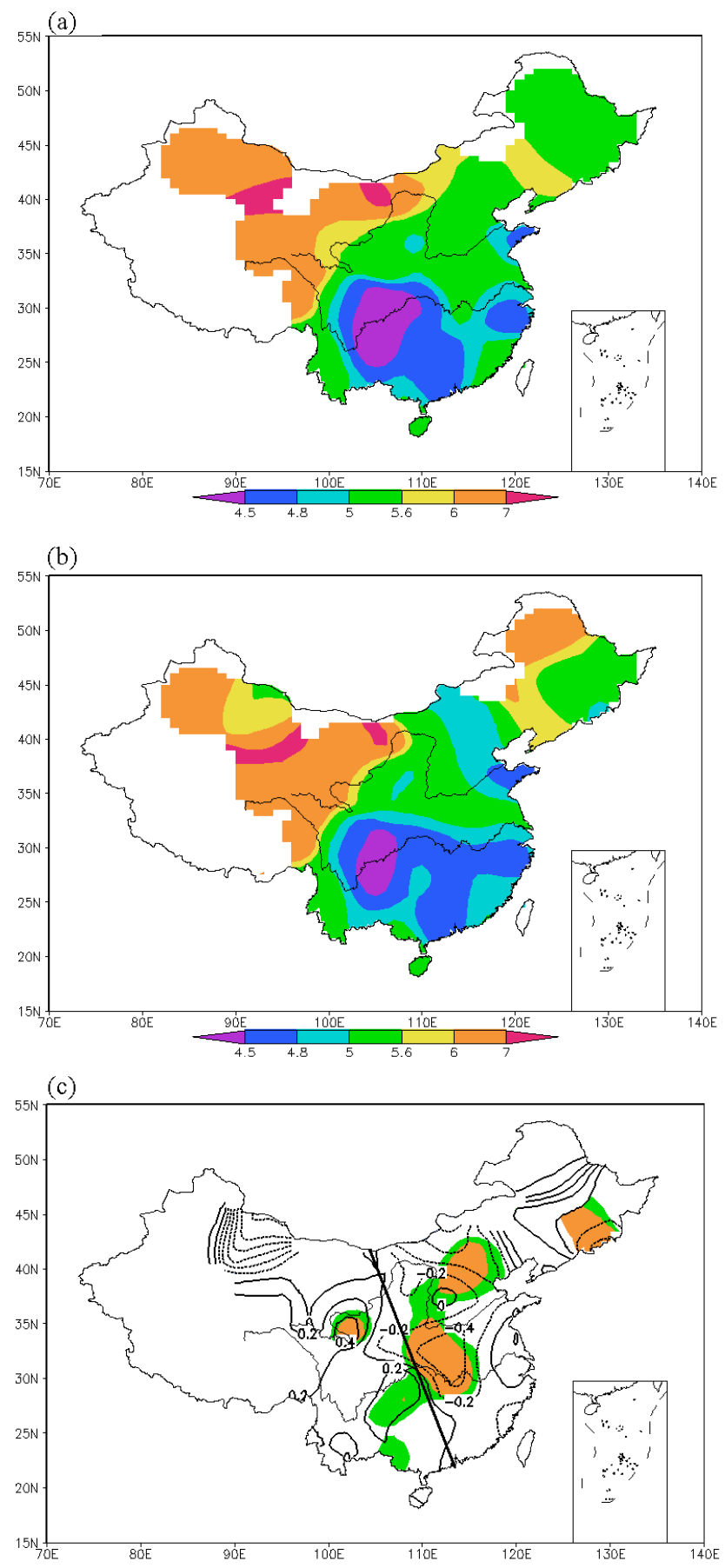

Fig. 5. Spatial distributions of the $\mathrm{pH}_{\mathrm{VWA}}$ values for 1992-1999 (a) and for 2000-2006 (b), and the differences between them (c). The green and yellow shadowed areas in (c) indicate areas in which the differences are significant at $90 \%$ and $95 \%$ level respectively, the real line is southeast-northwest line from $22^{\circ} \mathrm{N}, 112^{\circ} \mathrm{E}$ to $42^{\circ} \mathrm{N}$, $105^{\circ} \mathrm{E}$.

precipitation. The impacts of the East Asian Summer Monsoon and precipitation in MLYR on the variation in acidity of precipitation in Central China are addressed in the following sections. 

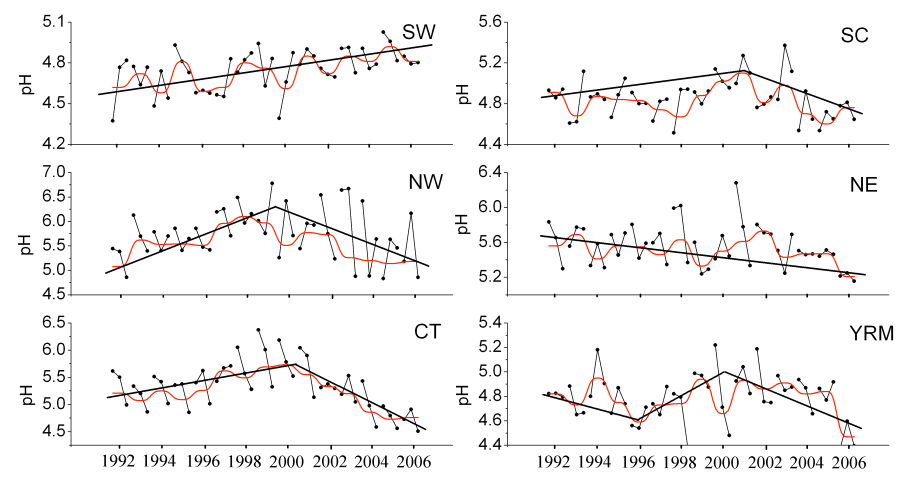

Fig. 6. Three point dash-dotted time series of $\mathrm{pH}_{\mathrm{VWA}}$ in the selected regions in summer during 1992-2006.

\subsection{Effects of summer monsoon and rainfall in YRD}

\subsubsection{Relationship between summer monsoon and pH}

The monsoon is an important component of the global circulation system. In monsoon regions, the local weather and climate, and especially precipitation, are strongly influenced by the monsoon circulation. In order to study the potential effects of the summer monsoon on acid rain in China, the East Asian Monsoon Index (EAMI)(Li and Zeng, 2002), which characterizes the summertime climate in China ( $\mathrm{Li}$ and Zeng, 2005), has been adopted by National Oceanic and Atmospheric Administration (NOAA), and is used to denote the intensity of summer monsoon.

Figure 7a shows the time series of EAMI (http://www.lasg. ac.cn/staff/ljp/data-monsoon/EASMI.htm). Based on this figure, we define years above the solid line (20 percent higher than the normal value " 1 ") as strong summer monsoon years (high MI), and those below the dashed line (20 percent lower than the normal value "1") as weak summer monsoon years (low MI). Figure 7b and c shows average spatial patterns of summer $\mathrm{pH}_{\mathrm{VwA}}$ in low and high MI years, respectively. The difference in summer $\mathrm{pH}$ VwA between low and high MI years is shown in Fig. 7d. In MLYR, the pHVwA values in high MI years are about $0.1 \sim 0.2$ lower than in low MI years. In $\mathrm{CT}$, the difference in $\mathrm{pH}$ VwA values is $0.2 \sim 0.4$, and in some areas it even exceeds 0.4 . These results indicate that the precipitation in YRL and Central China is more acidic in strong summer monsoon years than in weak years. It is known generally that in the strong monsoon years the climate in the Yangtze River Delta (YRD) is characterized by strong winds and little precipitation (Li and Zeng, 2005). Model simulations with different scenarios in the following sections are used to estimate how much these climate features contribute to the worsening of acid rain in Central China.

China relies heavily on coal combustion for energy and recently the volume of motor vehicles has increased sharply, leading to significant increases in emitted $\mathrm{SO}_{2}$ and $\mathrm{NO}_{\mathrm{x}}(\mathrm{Hao}$
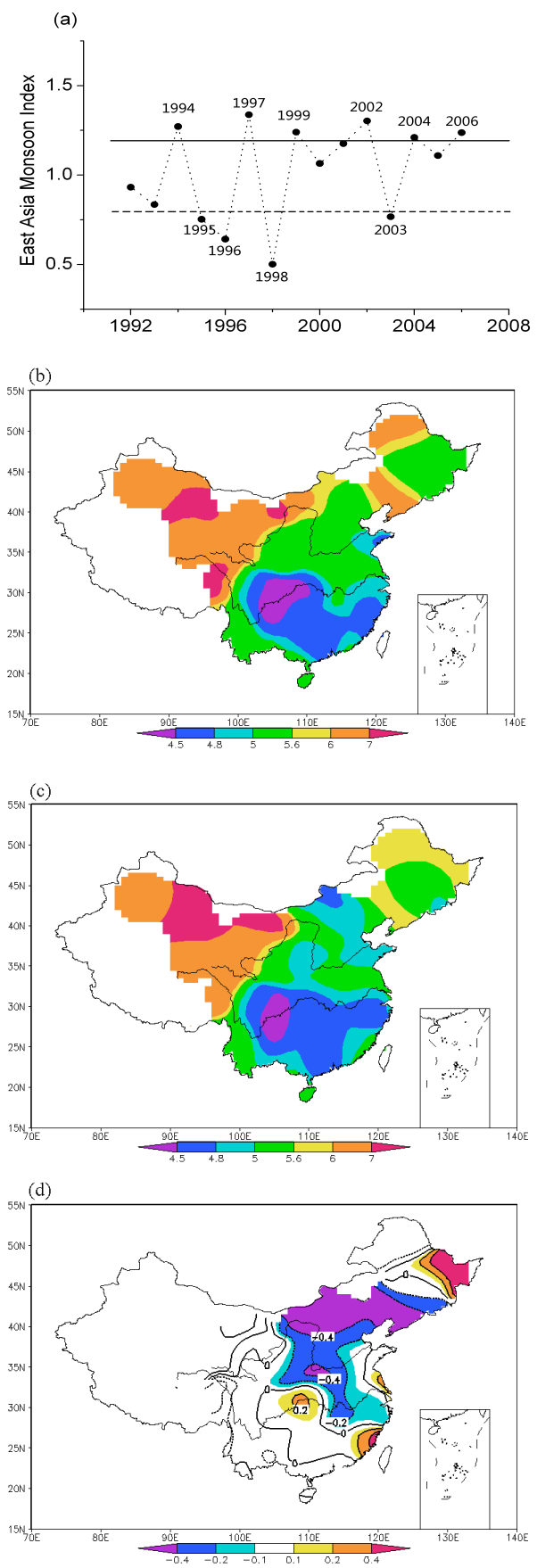

Fig. 7. Time series of EAMI (a), average spatial patterns of summer $\mathrm{pH}_{\text {VWA }}$ in weak (b) and strong (c) summer monsoon years, and the difference between strong and weak monsoon years $(\mathbf{d})$.

et al., 2001; Zhao et al., 2008). These air pollutants are the dominant precursors of acidic species, such as $\mathrm{SO}_{4}^{2-}$ and $\mathrm{NO}_{3}^{-}$ions, which control almost $90 \%$ of the acidity of precipitation in Southern and Central China(Wang and Wang, 1995, 1996; Wang and Xu, 2009; Zhang et al., 1996; Lei et al., 1997). We simulate the distribution of these two key gaseous 
pollutants $\left(\mathrm{SO}_{2}\right.$ and $\left.\mathrm{NO}_{2}\right)$ and ions $\left(\mathrm{SO}_{4}^{2-}\right.$ and $\left.\mathrm{NO}_{3}^{-}\right)$in low and high MI years for different scenarios (see Sect. 2.2) using the CMAQ model. Note that the neutralization of rain by aerosols is not considered here as alkaline aerosol are not significant in this area (only about $11 \%-25 \%$ ) compared to northern China (60\%-70\%) (Wang and Wang, 1995; Qin and Huang, 2001; Terada et al., 2002). Figure 8 shows the differences in the simulated $\mathrm{SO}_{4}^{2-}$ and $\mathrm{NO}_{3}^{-}$concentrations in rainwater between low and high MI years for the Normal and MC Scenarios. For the Normal Scenario, the simulated $\mathrm{SO}_{4}^{2-}$ and $\mathrm{NO}_{3}^{-}$concentrations in Central China are clearly lower in low MI years than in high MI years, as shown in Fig. 8a and $b$. The differences in the simulated $\mathrm{SO}_{2}$ and $\mathrm{NO}_{2}$ concentrations (not shown) have similar patterns. These differences may be attributed to differences in meteorological conditions, or pollution emissions, or both, between weak and strong monsoon years. The simulations for MC (varying meteorological conditions and fixed emission inventory) show similar patterns to the differences in the simulated $\mathrm{SO}_{4}^{2-}$ and $\mathrm{NO}_{3}^{-}$concentrations, but with reduced extent, as shown in Fig. $8 \mathrm{c}$ and d. This suggests that meteorological conditions related to the summer monsoon have caused higher concentrations of $\mathrm{SO}_{4}^{2-}$ and $\mathrm{NO}_{3}^{-}$in rainwater (and hence higher precipitation acidity) in Central China in high MI years. The differences in the $\mathrm{SO}_{4}^{2-}$ and $\mathrm{NO}_{3}^{-}$concentrations simulated for MC can be attributed solely to changes in the intensity of the summer monsoon, while those simulated for Normal can be attributed to intensity changes of the summer monsoon and to pollutant emissions. Supposing that the differences in the simulated $\mathrm{SO}_{4}^{2-}$ and $\mathrm{NO}_{3}^{-}$concentrations result in corresponding changes in the precipitation acidity in Central China, we can estimate the contribution of the summer monsoon to the change of precipitation acidity by comparing the values in Fig. 8c and d with those in Fig. 8a and b. We obtain a summer monsoon contribution of almost $65 \%$ (regional average of $-12.0 \mu \mathrm{mol} \mathrm{L}^{-1}$ in Fig. $8 \mathrm{c}$ and $-18.3 \mu \mathrm{mol} \mathrm{L}^{-1}$ in Fig. $8 \mathrm{a} ;-1.2 \mu \mathrm{mol} \mathrm{L}^{-1}$ in Fig. $8 \mathrm{~d}$ and $-2.0 \mu \mathrm{mol} \mathrm{L}^{-1}$ in Fig. 8b) to the change of precipitation acidity in Central China, specifically for stations in Central China the contributions are $16.23 \%-95.35 \%$ and are increased by closer to summer monsoon zone. Since the overall difference in $\mathrm{pH}$ VwA between low and high MI years is $0.33(0.13-0.65$ for stations in Central China), we deduce a regional average summer monsoon contribution of $0.22(0.12-0.42$ for stations in Central China) to the $\mathrm{pH}_{\mathrm{VWA}}$ difference, about $18-36 \%$ of the observed $\mathrm{pH}_{\mathrm{VWA}}$ change (0.6-1.2, see Fig. 1b) in Central China during 1992-2006. It is worthy to know that summer monsoon often affect the transportation of sulfate and nitrate in southeastern coast regions into Central China, while the alkaline substances in China originate mainly from northwest of China which are less influenced by summer monsoon. So, as we focused on the summer monsoon contribution on the precipitation acidity in Central China, the two dominantly anions (sulfate and nitrate) are facility to meet our purpose.
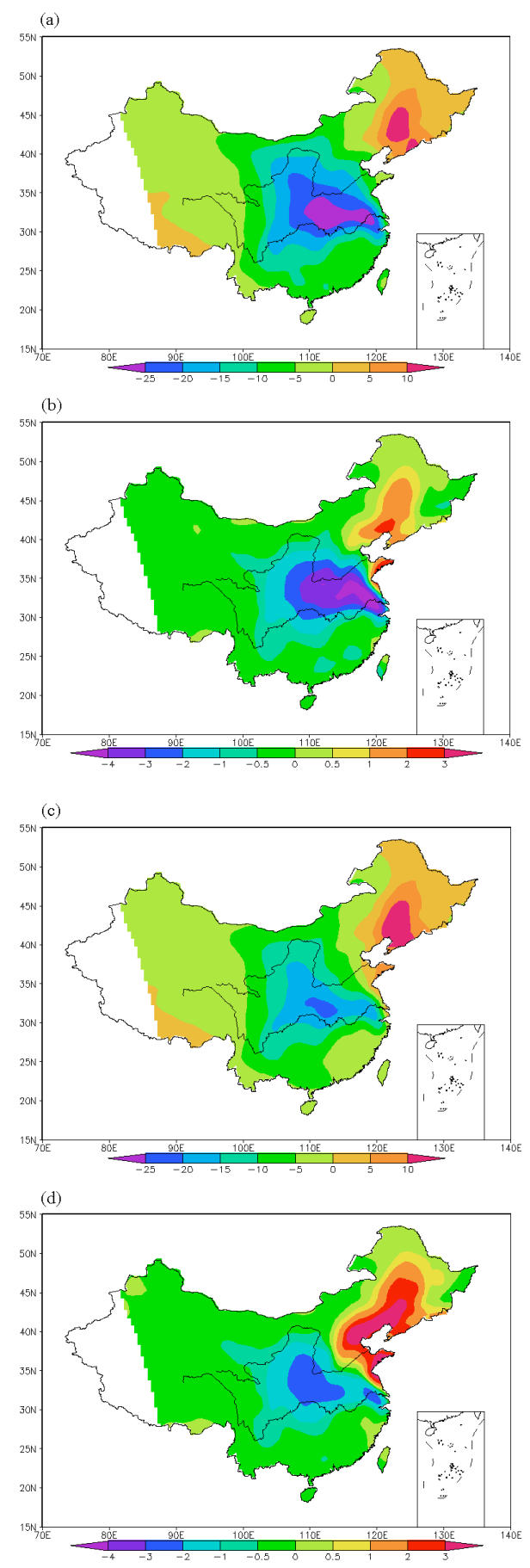

Fig. 8. Differences in the $\mathrm{SO}_{4}^{2-}$ and $\mathrm{NO}_{3}^{-}$concentration $\left(\mu \mathrm{mol} \mathrm{L}{ }^{-1}\right)$ between weak and strong summer monsoon years, simulated for the Normal Scenario $(\mathbf{a}, \mathbf{b})$ and the MC (c, d).

\subsubsection{Influence of MLYR rainfall on $\mathrm{pH}_{\mathrm{VwA}}$ change in Central China}

We used the SVD method (Sect. 2.4) to investigate the relationship between rainfall and $\mathrm{pH}_{\mathrm{VWA}}$ in China. The first pair 


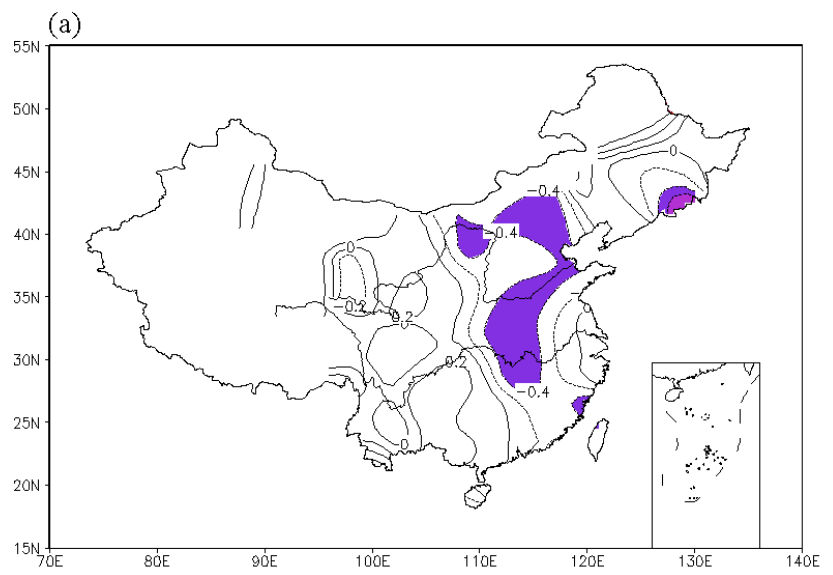

(b)

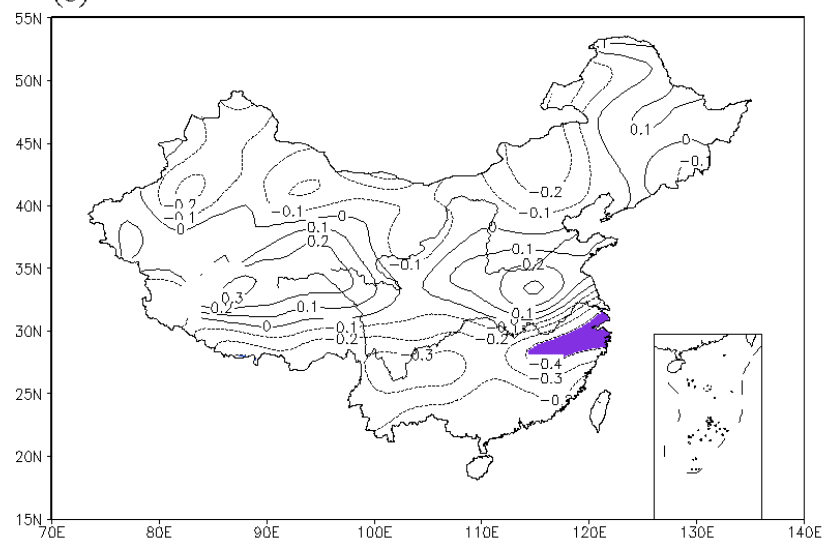

Fig. 9. The spatial patterns of left of first SVD eigenvectors (LFSE) (a) and right of first SVD eigenvectors (RFSE) (b) of summer rainfall and $\mathrm{pH}$ VWA in China.

of heterology correlation coefficients field is shown in Fig. 9 and the variance contribution is greater than 30\%. Fig. 9 shows that the spatial patterns of left of first SVD eigenvectors (LFSE), which stands for the correlations of $\mathrm{pH}$ VwA and time coefficient of rainfall in China, and right of first SVD eigenvectors (RFSE), which stands for the correlations of rainfall and time coefficient of $\mathrm{pH}_{\mathrm{VwA}}$ in China. Obviously, the $\mathrm{pH}$ vwA value in Central China is positively correlated to the rainfall in the MLYR (the correlation coefficients of two fields are both 0.4 ). This suggests that there is a relationship between the observed decrease of the pHvwA value in Central China during 1992-2006 and the decrease of rainfall in the MLYR. Actually, a decreasing trend of the rainfall was observed in the MLYR, as shown in Fig. 10a. The rainfall decreased significantly in this area with the rate of $1.2 \sim 1.8 \mathrm{~mm}$ per year during 1992 2006. As we discussed above, the $\mathrm{pH}$ value decreased significantly either in Central China. These two evidences prove the relationship mentioned above in detail.
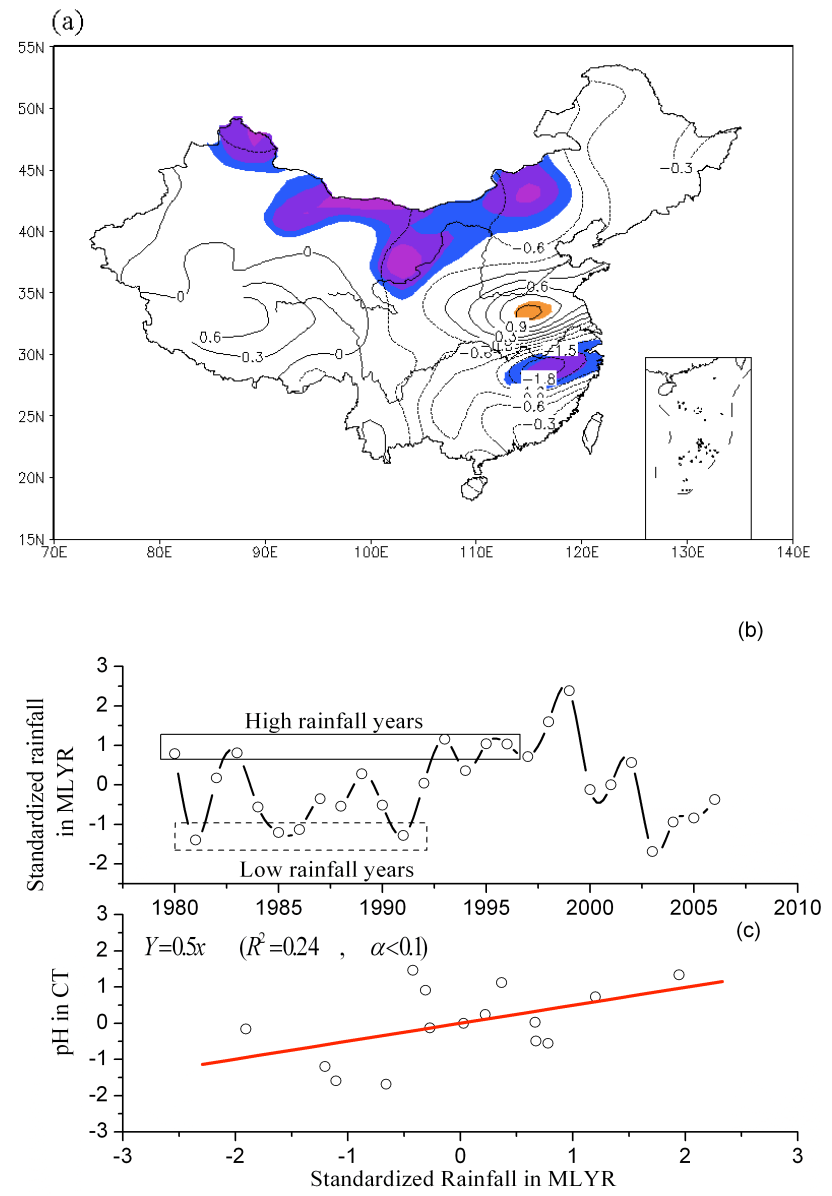

Fig. 10. (a) Changes in rainfall (mm year ${ }^{-1}$ ) during 1992-2006 with the shadowed areas indicating values significant at $90 \%$ level; (b) time series of the standardized rainfall in the MLYR during 1980-2006; (c) the correlation between rainfall in MLYR and $\mathrm{pH}_{\mathrm{VWA}}$ in Central China during 1992-2006.

To further support our hypothesis of the relationship, we calculated the total rainfall in the MLYR during 1980-2006 and standardized the time series by taking the difference between the total rainfall each year and the mean value over 1980-2006 and dividing by the standard deviation over this period. Figure 10b shows that the standardized rainfall varied within the range -1.5 to 1.5 before 1998 , underwent a sudden increase in 1998-1999, and then dropped to normal levels. For years up to 1997, we separately identify low and high rainfall years in Fig. 10b. We simulated the concentrations of $\mathrm{SO}_{4}^{2-}$ and $\mathrm{NO}_{3}^{-}$in rainwater for these low and high rainfall years using MC. Figure 11 shows the differences in the simulated rainwater $\mathrm{SO}_{4}^{2-}$ and $\mathrm{NO}_{3}^{-}$concentrations between the low and high rainfall years $\left(\mathrm{SO}_{4}^{2-}\right.$ and $\mathrm{NO}_{3}^{-}$concentrations in low rainfall years minus that in high rainfall years). It shows that both $\mathrm{SO}_{4}^{2-}$ and $\mathrm{NO}_{3}^{-}$concentrations have the greatest differences in Central China. Similar results are obtained by comparing the $\mathrm{SO}_{2}$ and $\mathrm{NO}_{2}$ concentrations simulated 
(a)

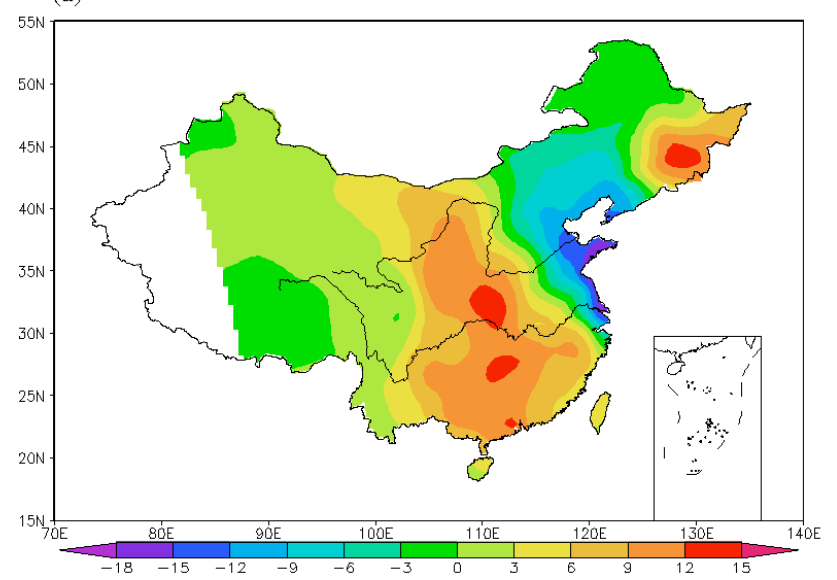

(b)

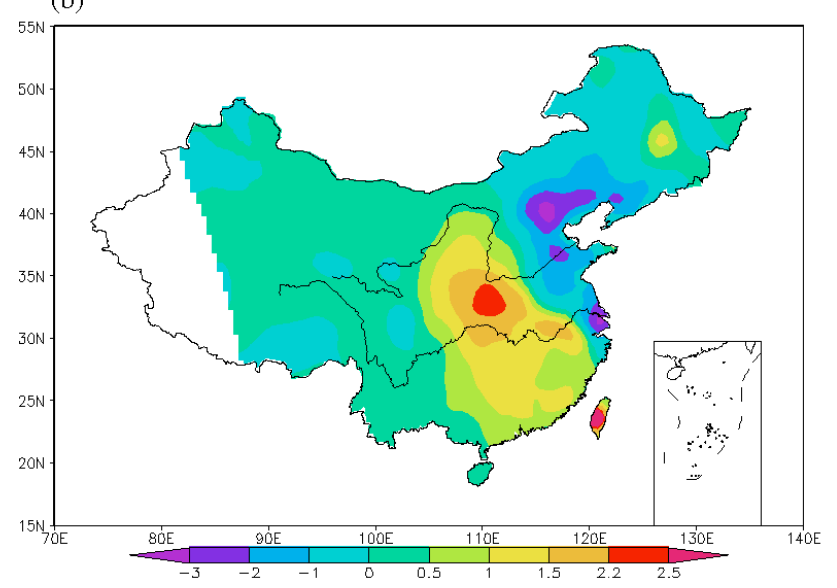

Fig. 11. Differences in the simulated rainwater $\mathrm{SO}_{4}^{2-}$ (a) and $\mathrm{NO}_{3}^{-}$ (b) concentrations $\left(\mu \mathrm{mol} \mathrm{L}{ }^{-1}\right)$ between the low and high rainfall years.

for low and high rainfall years. Moreover, we find that the pHvwA in Central China is positively correlated with rainfall in the MLYR with $R^{2}=0.24$ (significant at a $90 \%$ level) and explains $24 \%$ of the variance in $\mathrm{pH}$ in Central China, as shown in Fig. 10c. Based on these results we conclude that less rainfall in the MLYR may enhance the concentrations of acidic gases and their products in Central China, and hence increase the acidity of precipitation in this region. Statistically, about $24 \%$ of the variance in $\mathrm{pH}$ in Central China can be explained by this fluctuation in rainfall in the MLYR.

\subsection{Characteristics of modeled $\mathrm{SO}_{4}^{2-}$ and $\mathrm{NO}_{3}^{-}$ion con- centration during 1992-2003}

In Sect. 3.2, the contributions of changes in the summer monsoon and rainfall in the MLYR to the increase in precipitation acidity in Central China are studied using fixed pollutant emission intensities. However, the emissions of acidic gases $\left(\mathrm{SO}_{2}\right.$ and $\left.\mathrm{NO}_{\mathrm{x}}\right)$ are not stable, and hence the
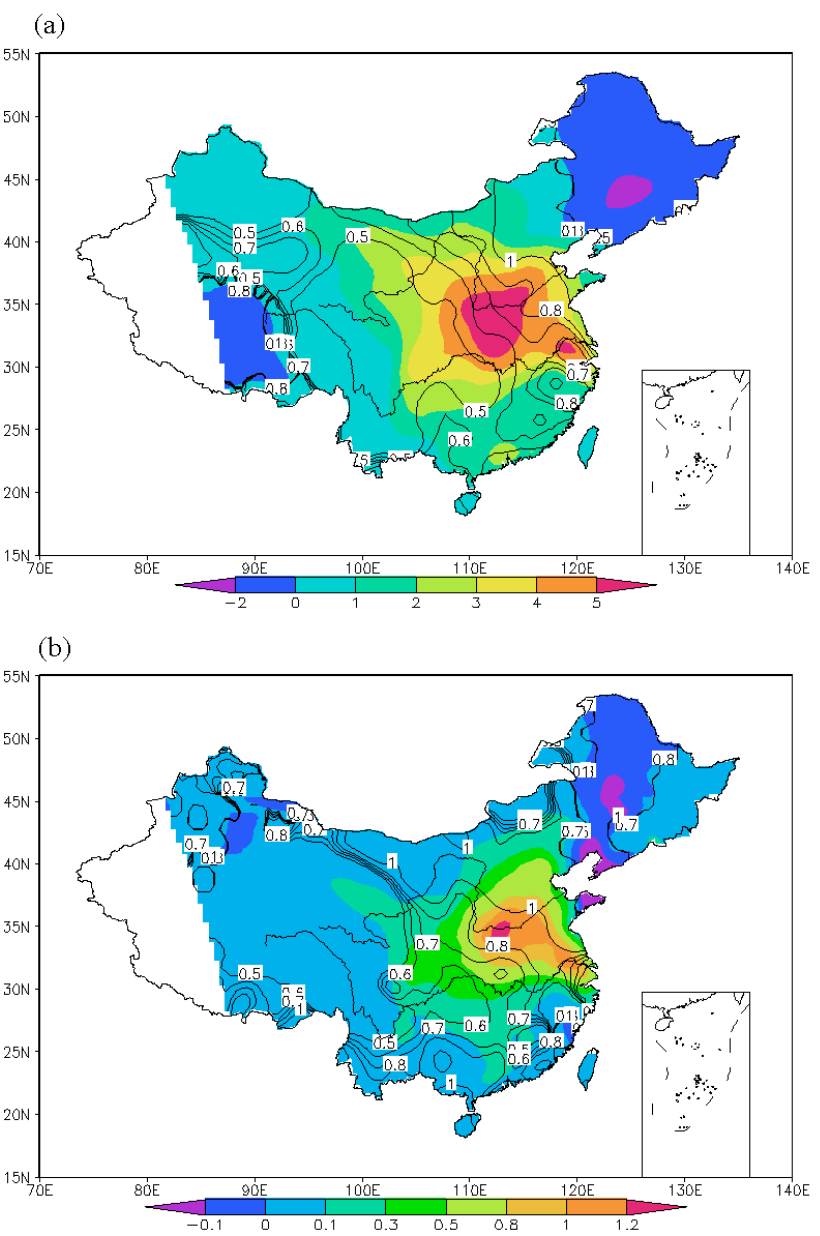

Fig. 12. Annual changes in rainwater $\mathrm{SO}_{4}^{2-}$ (a) and $\mathrm{NO}_{3}^{-}$(b) concentrations ( $\mu \mathrm{mol} \mathrm{L}{ }^{-1} \mathrm{y}^{-1}$ ) during 1992-2003.

impacts of changes in the emission intensities on precipitation acidity should also be addressed. For this purpose, we simulated rainwater $\mathrm{SO}_{4}^{2-}$ and $\mathrm{NO}_{3}^{-}$concentrations during 1992-2003 using the EC scenario (i.e., changing the emission inventory and using fixed meteorological conditions for 2000). Figure 12 shows the simulated annual changes in rainwater $\mathrm{SO}_{4}^{2-}$ and $\mathrm{NO}_{3}^{-}$concentrations during 1992-2003. The $\mathrm{SO}_{4}^{2-}$ and $\mathrm{NO}_{3}^{-}$concentrations in Central China show distinct increases at a rate of 3.1-5.1 $\mu \mathrm{mol} \mathrm{L}^{-1} \mathrm{y}^{-1}$ and $0.6-$ $1.3 \mu \mathrm{mol} \mathrm{L}-1 \mathrm{y}^{-1}$ (significant at a $95 \%$ level) for $\mathrm{SO}_{4}^{2-}$ and $\mathrm{NO}_{3}^{-}$, respectively.

To estimate the relative contribution of pollutants emissions to the changes in $\mathrm{SO}_{4}^{2-}$ and $\mathrm{NO}_{3}^{-}$concentrations, we divided the rates of change of $\mathrm{SO}_{4}^{2-}$ and $\mathrm{NO}_{3}^{-}$concentrations simulated for $\mathrm{EC}$ by those simulated for the Normal scenario. The results are shown as contours in Fig. 10 and suggest that about $60 \%-80 \%$ of the changes in $\mathrm{SO}_{4}^{2-}$ concentration and $70 \%-80 \%$ of the changes in $\mathrm{NO}_{3}^{-}$concentration in Central China are attributable to the changes in emissions. 


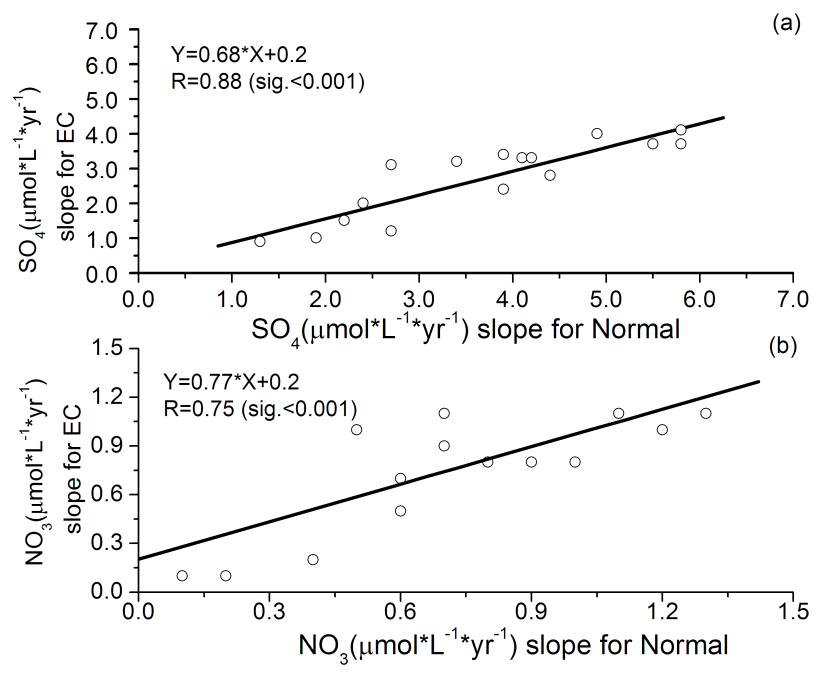

Fig. 13. Scatter plot between EC and Normal scene in 19 CMAARMN stations located in Central China of the slope of annual changes in rainwater $\mathrm{SO}_{4}^{2-}$ (a) and $\mathrm{NO}_{3}^{-}$(b) concentrations ( $\mu \mathrm{mol} \mathrm{L} \mathrm{y}^{-1}$ ) during 1992-2003.

In addition, we extract the 19 CMA-ARMN stations located in Central China to further support our results. Figure 13 shows the scatter plot between EC and Normal scene for sulfate and nitrate, 16 and 14 stations left for sulfate and nitrate respectively after removing any one that the correlation is not significant at the level of $99 \%$. We can conclude that the sulfate and nitrate are changed by $68 \%$ and $77 \%$ respectively which are within our scope. This confirms that most of the changes in $\mathrm{SO}_{4}^{2-}$ and $\mathrm{NO}_{3}^{-}$concentrations in Central China are caused by changes in emissions, at least during 19922003. Assuming that these changes in $\mathrm{SO}_{4}^{2-}$ and $\mathrm{NO}_{3}^{-}$ion concentrations contributed to changes in the $\mathrm{pH}$ of precipitation, we can conclude that changes in pollutant emissions contributed at least $60 \%$ of the variance of precipitation acidity in Central China during 1992-2003.

\section{Conclusions}

Summertime precipitation acidity data from CMA-ARMN stations between 1992 and 2006 have been analyzed using the EOFs method. We find that summertime $\mathrm{pH}$ in China experienced two different periods of variation, with $\mathrm{pH}$ increasing during 1992-1999 and decreasing during 2000-2006, which is similar to results obtained using the whole dataset (Tang et al., 2010). The most significant decrease of $\mathrm{pH}$ is found in Central China. To investigate the causes of the observed decrease of summertime $\mathrm{pH}$ in this region, the East Asian summer monsoon index and rainfall data are analyzed, together with the $\mathrm{pH}$ data, and simulations using CMAQ are performed for different scenarios.
We find that the East Asian summer monsoon can significantly affect the acidity of summer precipitation in Central China. For example, there is a difference of $0.33 \mathrm{in} \mathrm{pH}$ in Central China between years with weak and strong summer monsoons, and about $65 \%$ of this difference (i.e., 0.22) is related to the summer monsoon when using simulations with fixed emissions, accounting for $18-36 \%$ of the observed $\mathrm{pH}$ variation (0.6-1.2) in Central China during 1992-2006. Our SVD analysis and simulations reveal that there is a relationship between the $\mathrm{pH}$ in Central China and the rainfall in the MLYR. The $\mathrm{pH}$ value of precipitation in Central China is positively correlated with the rainfall in the MLYR, with $R^{2}=0.24$ (significant at a $90 \%$ level), suggesting that $24 \%$ of the variance in $\mathrm{pH}$ in Central China can be explained by the fluctuation in rainfall in the MLYR. However, the East Asian summer monsoon influences the rainfall in the Yangtze River regions, so the contribution of rainfall to the precipitation acidity in Central China may partially overlap with that of the summer monsoon.

The impacts of pollutant emissions on precipitation acidity in Central China are investigated using the CMAQ model with an annually varying emission inventory, and show that at least $60 \%$ of the variance of precipitation acidity in Central China can be attributed to changes in pollutant emissions. Therefore, increasing emissions of acidic species are the dominant factor contributing to the observed significant decrease of $\mathrm{pH}$ in Central China, and changes in meteorological factors, such as rainfall and other parameters related to the East Asian summer monsoon, play a less important but still significant role. Although this study estimates the impacts of the East Asian summer monsoon, rainfall in MLYR and pollutants emissions on the variation in $\mathrm{pH}$ in Central China, further studies are needed to confirm these effects and to investigate the type of acid rain in this area.

Acknowledgements. This work is supported by National Basic Research Program of China (2005CB422205 and 2005CB422202) and the Chinese Academy of Science (KZCX2-YW-205) and NSFC (40775077). We thank Liu Ying for providing the FORTRAN programs of the mathematical methods.

Edited by: L. Molina

\section{References}

Alter, O., Brown, P. O., and Botstein, D.: Singular value decomposition for genome-wide expression data processing and modeling, P. Natl. Acad. Sci. USA., 97, 10101-10106, 2000.

Browning, K. A., Allam, R. J., Ballard, S. P., Barnes, R. T. H., Bennetts, D. A., Maryon, R. H., Mason, P. J., Mckenna, D., Mitchell, J. F. B., Senior, C. A., Slingo, A., and Smith, F. B.: Environmental-Effects from Burning Oil-Wells in Kuwait, Nature, 351, 363-367, 1991.

Byun, D. W. and Ching, J. K. S.: Science algorithms of the EPA Models-3 community multiscale air quality (CMAQ) modeling 
system, EPA/600/R-99/030, Natl. Exposure Res. Lab., Research Triangle Park, N. C., 1999.

Calbet, X. and Schlüssel, P.: Technical note: analytical estimation of the optimal parameters for the EOF retrievals of the IASI Level 2 Product Processing Facility and its application using AIRS and ECMWF data, Atmos. Chem. Phys., 6, 831-846, doi:10.5194/acp-6-831-2006, 2006.

Cotton, W. R., Pielke, R. A., Walko, R. L., Liston, G. E., Tremback, C. J., Jiang, H., McAnelly, R. L., Harrington, J. Y., Nicholls, M. E., Carrio, G. G., and McFadden, J. P.: RAMS 2001: Current status and future directions, Meteorol. Atmos. Phys., 82, 5-29, 2003.

Davies, T. D., Dorling, S. R., Pierce, C. E., Barthelmie, R. J., and Farmer, G.: The Meteorological Control on the Anthropogenic Ion Content of Precipitation at 3 Sites in the UK - the Utility of Lamb Weather Types, Int. J. Climatol., 11, 795-807, 1991.

Dayana, U. and Lamb, D.: Influences of atmospheric circulation on the variability of wet sulfate deposition, Int. J. Climatol., 28, 1315-1324 2008.

Ding, G. A., Xu, X. B., and Fang, X. M.: The current status and trends of acid rain in China, Chinese Sci. Bul., 42, 169-173, 1997 (in Chinese).

Ding, G. A., Xu, X. B., and Wang, S. F.: Database from the acid rain network of China Meteorological Administration and its preliminary analysis, J. App. Meteoro. Sci., 15(supplement), 85-94, 2004 (in Chinese).

Ding, Y. and Jiang, Z.: Generality of Singular Value Decomposition in Diagnostic Analysis of Meteorological Field, Acta. Meteorol. Sin., 54, 365-372, 1996 (in Chinese).

Gao, C. L., Yin, H. Q., Ai, N. S., and Huang, Z. W.: Historical Analysis of $\mathrm{SO}_{2}$ Pollution Control Policies in China, Environ. Manage., 43, 447-457, 2009.

Gianelli, S. M., Carlson, B. E., and Lacis, A. A.: Using EOF analysis to qualitatively analyze, and identify inhomogeneities in data from ground-based aerosol monitoring instruments, J. Geophys. Res., 112, D20210, doi:10.1029/2006JD008300, 2007.

Gu, Z., Fen, G., Gu, J., and Shi, N.: EOF of 500 hPa Wind Fields and Its Relationship to Large Scale Abnormal Climate in Midsummer of China, Scientia. Meteorologica. Sinica., 27, 245-252, 2007 (in Chinese).

Hao, J. M., Wang, S. X., Liu, B. J., and He, K. B.: Designation of sulfur dioxide and Acid Rain Pollution Control Zones and its impacts on energy industry in China, J. Chem. Eng. Jpn., 34, 1108-1113, 2001.

He, Y., Uno, I., Wang, Z., Ohara, T., Sugirnoto, N., Shimizu, A., Richter, A., and Burrows, J. P.: Variations of the increasing trend of tropospheric $\mathrm{NO}_{2}$ over central east China during the past decade, Atmos. Environ., 41, 4865-4876, 2007.

He, Y. J., Uno, I., Wang, Z. F., Pochanart, P., Li, J., and Akimoto, H.: Significant impact of the East Asia monsoon on ozone seasonal behavior in the boundary layer of Eastern China and the west Pacific region, Atmos. Chem. Phys., 8, 7543-7555, doi:10.5194/acp-8-7543-2008, 2008.

Huang, K., Zhuang, G. S., Xu, C., Wang, Y., and Tang, A. H.: The chemistry of the severe acidic precipitation in Shanghai, China, Atmos. Res., 89, 149-160, 2008.

Huang, M., Shen, Z., and Liu, S.: A study on the formation processes of acid rain in some areas of Southwest China, Sci. Atmos. Sin., 19, 359-366, 1995 (in Chinese).
Jordi, A., Basterretxea, G., and Angles, S.: Influence of ocean circulation on phytoplankton biomass distribution in the Balearic Sea: Study based on Sea-viewing Wide Field-of-view Sensor and altimetry satellite data, J. Geophys. Res-Oceans., 114, C11005, doi:10.1029/2009JC005301, 2009.

Khemani, L. T., Momin, G. A., Rao, P. S. P., Pillai, A. G., Safai, P. D., Mohan, K., and Rao, M. G.: Atmospheric Pollutants and Their Influence on Acidification of Rain Water at an IndustrialLocation on the West-Coast of India, Atmos. Environ., 28, 31453154, 1994.

Larssen, T., Lydersen, E., Tang, D. G., He, Y., Gao, J. X., Liu, H. Y., Duan, L., Seip, H. M., Vogt, R. D., Mulder, J., Shao, M., Wang, Y. H., Shang, H., Zhang, X. S., Solberg, S., Aas, W., Okland, T., Eilertsen, O., Angell, V., Liu, Q. R., Zhao, D. W., Xiang, R. J., Xiao, J. S., and Luo, J. H.: Acid rain in China, Environ. Sci. Technol., 40, 418-425, 2006.

Lei, H. C., Tanner, P. A., Huang, M. Y., Shen, Z. L., and Wu, Y. X.: The acidification process under the cloud in Southwest China: observation results and simulation, Atmos. Environ., 31, 851861, 1997.

Li, J. and Zeng, Q.: A unified monsoon index, Geophys. Res. Lett., 29, 1151-1154, 2002.

Li, J. and Zeng, Q.: A New Monsoon Index , Its Interannual Variability and Relation with Monsoon Precipitation, Clim. Environ. Res., 10, 42-46, 2005.

Lin, M. Y., Oki, T., Holloway, T., Streets, D. G., Bengtsson, M., and Kanae, S.: Long-range transport of acidifying substances in East Asia - Part I - Model evaluation and sensitivity studies, Atmos. Environ., 42, 5939-5955, 2008.

Liu, B. J., Hao, J. M., and He, K. B.: Study on designation of acid rain and $\mathrm{SO}_{2}$ pollution control areas and policy implementation, Acta. Sci. Circumst., 18, 1-7, 1998 (in Chinese).

Liu, C. Q., Lang, Y. C., Satake, H., Wu, J. H., and Li, S. L.: Identification of anthropogenic and natural inputs of sulfate and chloride into the karstic ground water of Guiyang, SW China: Combined delta Cl-37 and delta S-34 approach, Environ. Sci. Technol., 42, 5421-5427, 2008.

Ohara, T., Akimoto, H., Kurokawa, J., Horii, N., Yamaji, K., Yan, X., and Hayasaka, T.: An Asian emission inventory of anthropogenic emission sources for the period 1980-2020, Atmos. Chem. Phys., 7, 4419-4444, doi:10.5194/acp-7-4419-2007, 2007.

Ohara, T., Yamaji, K., Uno, I., Tanimoto, H., Sugata, S., Nagashima, T., Kurokawa, J.-I., Horii, N., and Akimoto, H.: LongTerm Simulations of Surface Ozone in East Asia During 19802020 with CMAQ and REAS Inventory, in: Air Pollution Modeling and Its Application XIX, edited by: Borrego, C. and Miranda, A. I., NATO Science for Peace and Security Series, Springer Netherlands, 136-144, 2008.

Ohara, T.: Long-term trends for anthropogenic $\mathrm{SO}_{2}$ emissions and sulfur depositions in East Asia, International Workshop on Atmospheric Modeling Research in East Asia, 18-19 March 2010, Express Holiday Inn City Center Dalian, China, 2010.

Pielke, R. A., Cotton, W. R., Walko, R. L., Tremback, C. J., Lyons, W. A., Grasso, L. D., Nicholls, M. E., Moran, M. D., Wesley, D. A., Lee, T. J., and Copeland, J. H.: A Comprehensive Meteorological Modeling System - Rams, Meteorol. Atmos. Phys., 49, 69-91, 1992.

Prohaska, J.: A technique for analyzing the linear relationships be- 
tween two meteorological fields, Mon. Weather Rev., 104, 13451353, 1976.

Qin, G. Y. and Huang, M. Y.: A study on rain acidification processes in ten cities of China, Water. Air. Soil. Poll., 130, 163-174, 2001.

Quan, J., Zhang, X., and Duan, N.: Numerical modeling of sulfur deposition in south and southwest China, Plateau Meteorology., 26, 326-332, 2007 (in Chinese).

Quan, J. N., Zhang, X. S., Zhang, Q., Guo, J. H., and Vogt, R. D.: Importance of sulfate emission to sulfur deposition at urban and rural sites in China, Atmos. Res., 89, 283-288, 2008.

Rai, H. C., Sharma, A., and Sharma, V. M.: Studies on Temporal Variation of Acid Precipitation in Delhi, Asian. J. Chem., 21, 5391-5398, 2009.

Ravichandran, C. and Padmanabhamurty, B.: Acid Precipitation in Delhi, India, Atmos. Environ., 28, 2291-2297, 1994.

Rodhe, H., Dentener, F., and Schulz, M.: The global distribution of acidifying wet deposition, Environ. Sci. Technol., 36, 43824388, 2002.

SEPA: Report on the status quo of the environment in China from 1990 to 2006, available at: http://jcs.mep.gov.cn/hjzl/zkgb/, last access: 3 June 2010.

Seqheira, R. and Lai, C.: Small-scale spatial variability in the representative composition of rainwater within urban Hong Kong, Atmos. Environ., 32, 133-144, 1998.

Shi, X., Xu, X., and Xie, L. A.: Interdecadal Spatial-Temporal Change Trend of East Asian Winter Monsoon in the Last 40 Years, Chinese. J. Atmos. Sci., 31, 747-756, 2007 (in Chinese).

Tang, J. C. H. B., Yu, X. L., Wang, S., Yao, P., Lv, B., Xu, X. B., and Ding, G.: Evaluation of results of station inter-comparison with blind samples in Acid Rain Monitoring Network in China, Meteoro. Monthly, 33, 75-83, 2007 (in Chinese).

Tang, J., Xu, X., Ba, J., and Wang, S.: Trends of the precipitation acidity over China during 1992-2006, Chinese. Sci. Bul., 5, 1800-1807, doi:10.1007/s11434-009-3618-1, 2010.

Tanimoto, H., Ohara, T., and Uno, I.: Asian anthropogenic emissions and decadal trends in springtime tropospheric ozone over Japan: 1998-2007, Geophys. Res. Lett., 36, L23802, doi:10.1029/2009GL041382, 2009.

Terada, H., Ueda, H., and Wang, Z. F.: Trend of acid rain and neutralization by yellow sand in East Asia - a numerical study, Atmos. Environ., 36, 503-509, 2002.

Tiwari, S., Kulshrestha, U. C., and Padmanabhamurty, B.: Monsoon rain chemistry and source apportionment using receptor modeling in and around National Capital Region (NCR) of Delhi, India, Atmos. Environ., 41, 5595-5604, 2007.

Vogt, R. D., Seip, H. M., Larssen, T., Zhao, D. W., Xiang, R. J., Xiao, J. S., Luo, J. H., and Zhao, Y.: Potential acidifying capacity of deposition - Experiences from regions with high NH4+ and dry deposition in China, Sci. Total. Environ., 367, 394-404, 2006.

Wai, K. M. and Tanner, P. A.: Relationship between the ionic composition in $\mathrm{PM}_{1} 0$ and the synoptic-scale and mesoscale weather conditions in a south China coastal city: a 4-year study, J. Geophys. Res., 110, D18210, doi:10.1029/2004JD005385, 2005.

Wang, Q.-Q. and Chen, S.-D.: SVD Analysis of the Relationship Between Jiangnan Rainy Season Precipitation and Sea Surface Temperature in the Tropical Oceans, Arid. Meteorol., 22, 11-16, 2004 (in Chinese).

Wang, T. J., Jiang, F., Li, S., and Liu, Q.: Trends in air pollution during 1996-2003 and cross-border transport in city clusters over the Yangtze River Delta region of China, Terr. Atmos. Ocean. Sci., 18, 995-1009, 2007.

Wang, W. X. and Wang, T.: On the origin and the trend of acid precipitation in China, Water. Air. Soil. Poll., 85, 2295-2300, 1995.

Wang, W. X. and Wang, T.: On acid rain formation in China, Atmos. Environ., 30, 4091-4093, 1996.

Wang, W. X. and Xu, P. J.: Research progress in precipitation chemistry in China, Prog. Chem., 21, 266-281, 2009 (in Chinese).

Wang, Z. F., Akimoto, H., and Uno, I.: Neutralization of soil aerosol and its impact on the distribution of acid rain over east Asia: Observations and model results, J. Geophys. Res., 107(D19), 4389, doi:10.1029/2001JD001040, 2002.

Xie, Z. Q., Du, Y., Zeng, Y., Li, Y. C., Yan, M. L., and Jiao, S. M.: Effects of precipitation variation on severe acid rain in southern China, J. Geogr. Sci., 19, 489-501, 2009.

Yamaji, K., Ohara, T., Uno, I., Tanimoto, H., Kurokawa, J., and Akimoto, H.: Analysis of the seasonal variation of ozone in the boundary layer in East Asia using the Community Multiscale Air Quality model: What controls surface ozone levels over Japan?, Atmos. Environ., 40, 1856-1868, 2006.

Yeung, M. C., Lee, S. C., Lun, B. H., and Tanner, P. A.: Summer rain events in south-east Asia: Spatial and temporal variations, Atmos. Res., 86, 241-248, 2007.

Zhang, C., Wang, S., and Xing, J.: Current status and future projections of $\mathrm{NO}_{\mathrm{x}}$ emissions from energy related industries in China, Acta. Sci. Circumst., 28, 2470-2479, 2008 (in Chinese).

Zhang, G., Zeng, G. M., Du, C. Y., Jiang, Y. M., Su, X. K., Xiang, R. J., Huang, L., Xu, M., and Zhang, C.: Deposition patterns in bulk precipitation and throughfall in a subtropical mixed forest in central-south China, Forestry, 80, 211-221, 2007.

Zhang, M. G., Uno, I., Yoshida, Y., Xu, Y. F., Wang, Z. F., Akimoto, H., Bates, T., Quinn, T., Bandy, A., and Blomquist, B.: Transport and transformation of sulfur compounds over East Asia during the TRACE-P and ACE-Asia campaigns, Atmos. Environ., 38, 6947-6959, 2004

Zhang, M. G., Pu, Y. F., Zhang, R. J., and Han, Z. W.: Simulation of sulfur transport and transformation in East Asia with a comprehensive chemical transport model, Environ. Modell. Softw., 21, 812-820, 2006a.

Zhang, M. G., Uno, I., Zhang, R. J., Han, Z. W., Wang, Z. F., and Pu, Y. F.: Evaluation of the Models-3 Community Multi-scale Air Quality (CMAQ) modeling system with observations obtained during the TRACE-P experiment: Comparison of ozone and its related species, Atmos. Environ., 40, 4874-4882, $2006 \mathrm{~b}$.

Zhang, F. Z., Zhang, J. Y., Zhan, H. R., Ogura, N., and Ushikubo, A.: Chemical composition of precipitation in a forest area of Chongqing, Southwest China, Water Air Soil Poll., 90, 407-415, 1996.

Zhao, D. W., Xiong, J. L., Xu, Y., and Chan, W. H.: Acid-Rain in Southwestern China, Atmos. Environ., 22, 349-358, 1988.

Zhao, Y., Wang, S. X., Duan, L., Lei, Y., Cao, P. F., and Hao, J. M.: Primary air pollutantemissions of coal-fired power plants in China: current status and future prediction, Atmos. Environ., 42, 8442-8452, 2008. 